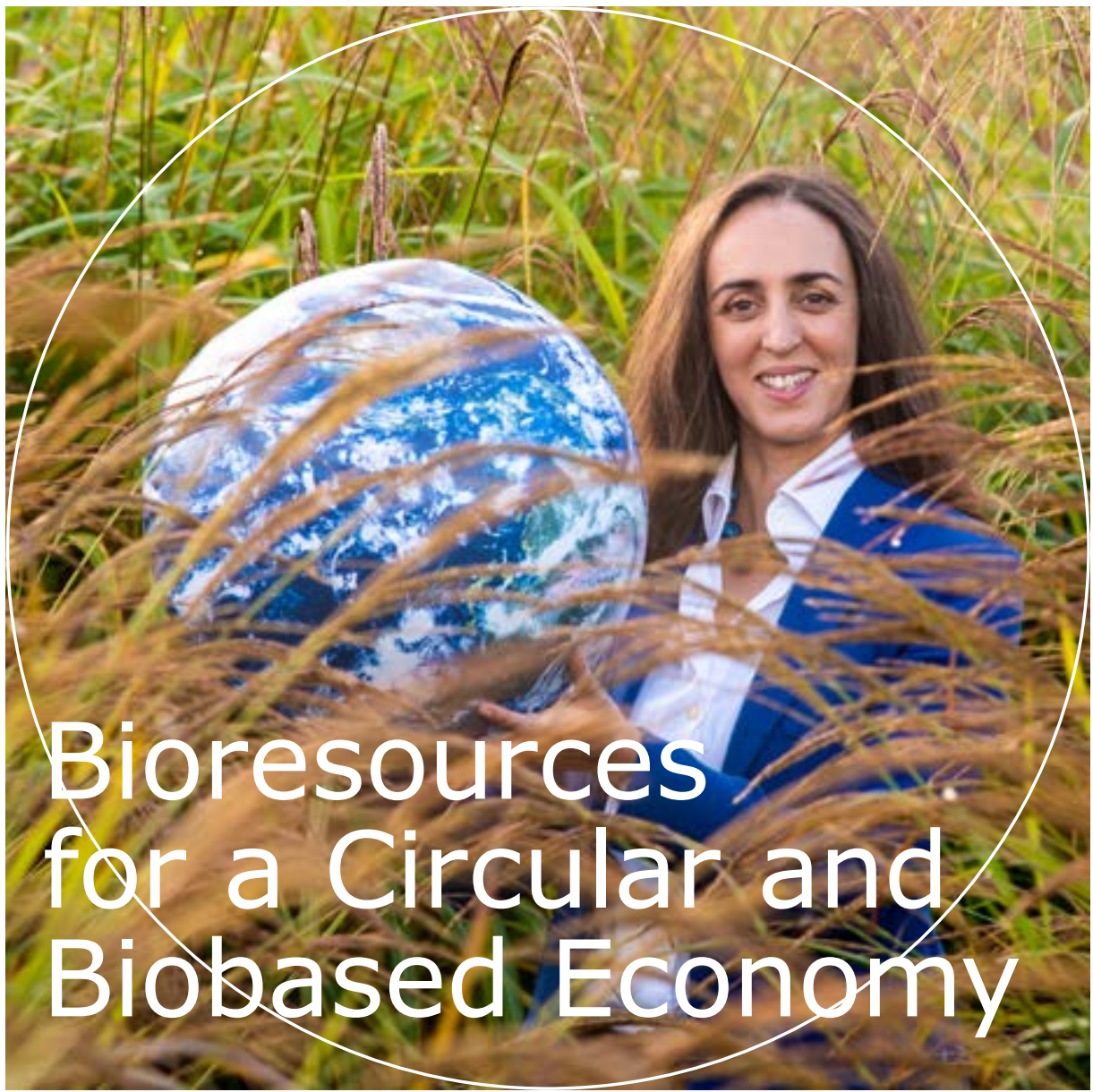

Prof.dr Luisa M. Trindade

Inaugural lecture upon taking up the position of Personal Professor of Bioresources Breeding and Genetics at Wageningen University \& Research on 29 August 2019 



\section{Bioresources for a Circular and Biobased Economy}

\section{Prof.dr Luisa M. Trindade}

Inaugural lecture upon taking up the position of Personal Professor of

Bioresources Breeding and Genetics at Wageningen University \& Research on 29 August 2019 
DOI https://doi.org/10.18174/538681

ISBN 978-94-6395-677-2

(C) 2019 Prof.dr. Luisa M. Trindade; WU. All rights reserved. No parts of this publication may be reproduced by print, photocopy, stored in a retrieval system or transmitted by any means without the prior written permission of the author. 


\section{Bioresources for a Circular and Biobased Economy}

Dear Rector Magnificus, colleagues, friends, family, ladies and gentlemen, Welcome! I am honoured to stand in the Aula of Wageningen University \& Research (WUR) to present my inaugural lecture upon taking up the position of Personal Professor of "Bioresources Breeding and Genetics". During my lecture I will take you on a tour to the plants of the future and how they can be better designed to meet our future demands, both for food and non-food applications.

\section{The need for better plants}

We are a in changing world and we are facing major global challenges crossing borders and sectors. We have an increasing population that is projected to reach 1o billion by 2050. This means that we have an increase in the demands for food, and an important question is whether with our current production systems we can we feed these 1o billion people healthily, equitably and sustainably. The production of more agricultural products require more natural resources, in particular water. We need to question ourselves on whether we can cope with this future increasing demand for water? Besides water we also need more energy. Energy for our production systems, to replace fossil oil and to address the needs of the growing population coming out of poverty. Can we produce energy for these increasing demands? On top of this we are facing a climate change and we need to interrogate ourselves whether we will be able to mitigate and adapt to climate change. Finally we need to understand whether we can do all this in the context of redressing the decline in biodiversity and preserving the ecosystem?

I believe we can, but to achieve that we have to change the way we organize our economy and society, we need a transition to a Resource Use Efficient (RUE) Circular Economy. 


\section{A Resource-Use-Efficient Circular Economy}

A Circular Economy covers all sectors and systems that rely on biological resources, and at the basis is efficient use and re-use (recycling) of resources such as nutrients, water and carbon (Figure 1). It implies zero waste and the replacement of fossil by sustainable biological feedstock's.

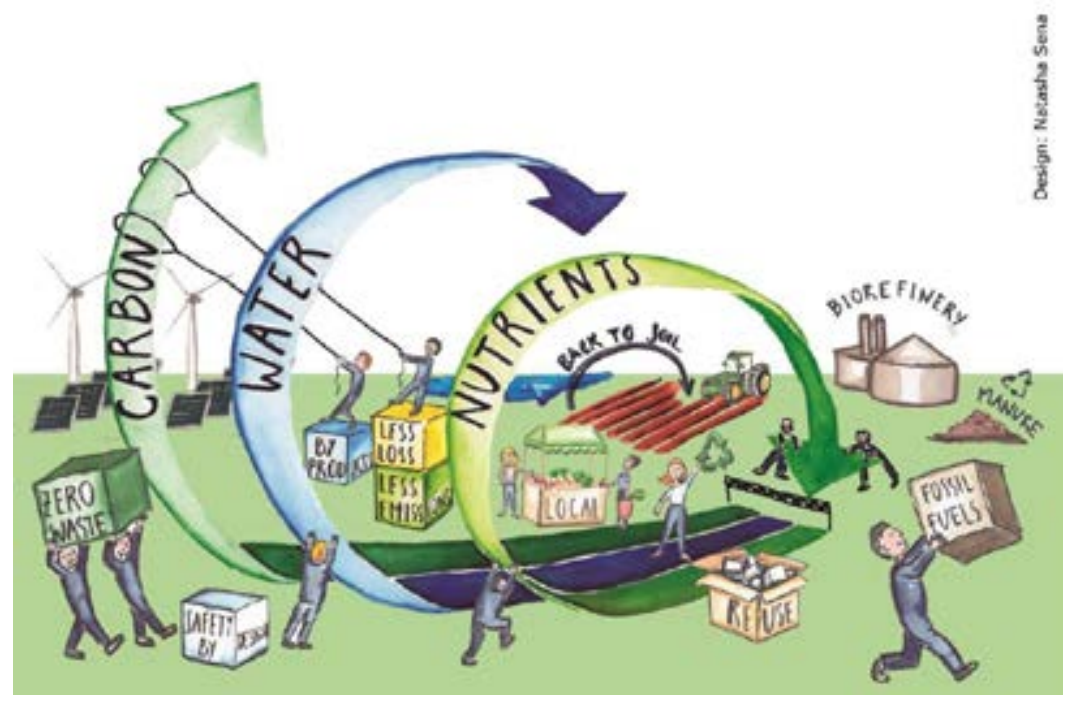

Figure 1: A Circular Economy. Illustration WUR investing theme Connected Circularity.

Nutrients are required for agricultural production and we have to make sure they will get back to the soil at the end of the cycle. Producing locally can partly solve this issue but in a global market we need to think about new technologies on how we can return the nutrients to the soil when agricultural products are cultivated and consumed in different places in the globe. We also need to develop technologies that enable efficient use of the nutrients from manure and side/waste streams of biorefineries.

To be efficient in the use of water we need to design new systems that enable that, and in particular the efficient use of drink water. Very importantly we need to close the Carbon cycle by i) reducing carbon emissions, through replacing fossil by sustainable biological resources; ii) reducing carbon losses, by using all the biomass efficiently, including the by-products and ensuring a zero waste; iii) re-using products, what we call cascading, e.g recycling cloths to remake new cloths or other products. In fact we need to go beyond carbon neutrality, by developing carbon fixation methods both within the primary production and by developing new 
C-based products, to prevent or limit the consequences of climate change. This will be the drive for the renewal of our industries, the modernization of our primary production systems and will enable protection of the environment and enhance biodiversity. One final aspect that we need to consider is safety, a circular system needs to be safe by design.

A Circular Economy requires a concerted action of all sectors and these sectors are connected in 3 main components (Figure 2). A first component is the design of novel aquatic and terrestrial production systems, and the optimization of marine agricultural and forestry bioresources. A second component is the valorisation of biomass, thus of the optimized bioresources, and that comprises the development of novel processes and products. A third component is the development of the building blocks of a circular climate robust society and that comprises the development of different socio-economic models. Our current society is characterised by an obsolescent economy meaning that we consume more, and more often than we need, and resources are wasted. To enter a Circular and Biobased Economy, new business models and policies need to be developed. We require the development new concepts and frame them in the context of a resource use efficient society. It also requires a good collaboration and integration between the different sectors.

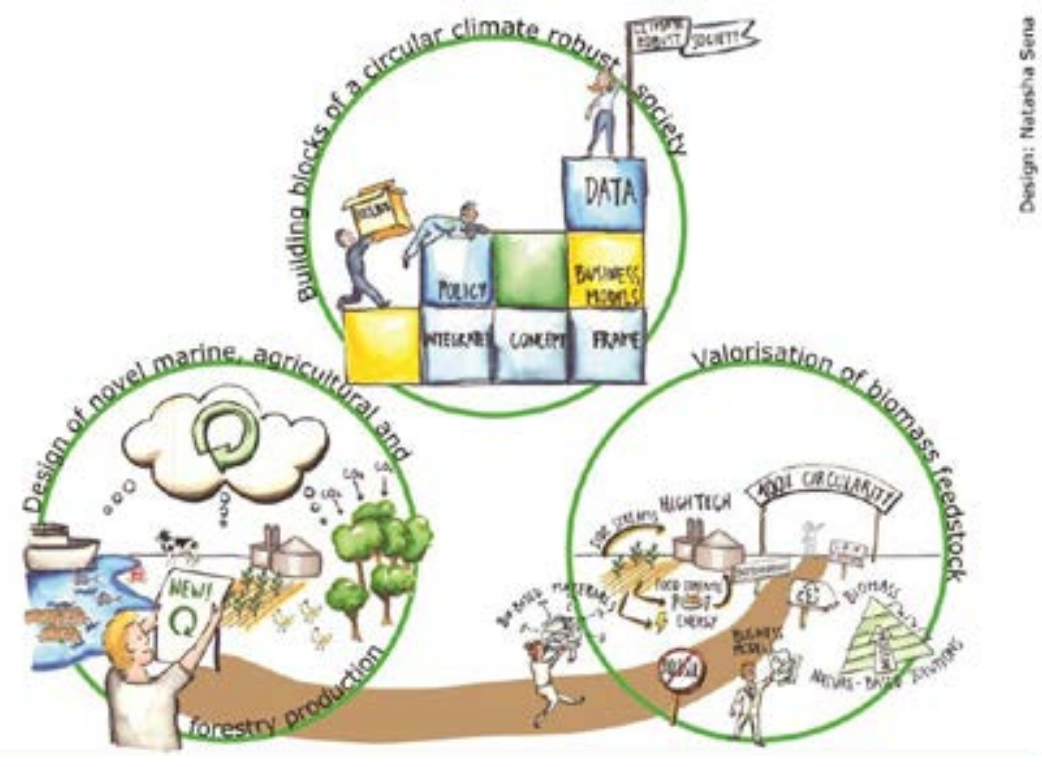

Figure 2: Main components of a Circular Economy. Illustration WUR investing theme Connected Circularity 


\section{The Plants of the Future}

At the basis of a Circular Economy are plants. Current crops have been designed for different purposes and are far from optimal for the new demands of the Circular Bioeconomy. They need, therefore, to be re-designed. The plants of the future will, on the one hand, require less inputs because they are more efficient in the use of these inputs, such as water and fertilizers. They are also more efficient in the use of sunlight as they photosynthesize more efficiently. On the other hand these plants need to produce more, besides fulfilling our demands in food and feed, plant biomass will be used as feedstock to replace fossil oil derived products such as chemicals, materials, energy, and fuels. Designing such crops requires new breeding methods and strategies, and to develop such tools we need to better understand the mechanisms underlying the synthesis of different molecules in the plant, and how the synthesis of each molecule is related to the synthesis of other molecules, what we call carbon partitioning.

I see the "plant as a plant", thus as a bio-factory of different compounds. These compounds comprise primary metabolites that are essential for the survival of the plant, such as carbohydrates (from simple mono-di-oligo saccharides and starch to very complex cell walls polysaccharides), lipids (fatty acids, phospholipids and waxes) and proteins (such as enzymes). Plants also synthesize secondary metabolites that, although not essential for the survival of the plant, play very important roles in plant defence against biotic and abiotic stresses. Apart from these important roles for the plant cell all these compounds are the basis of life on earth, and in particular they are the feedstocks required to fulfil human needs for food, feed and non-food products. Each component has different functions and functionalities and that makes them suitable as building block to make different products.

My research focuses on i) understanding the mechanisms behind the synthesis and regulation of each of these compounds; ii) understand the relationships between the different components, thus partitioning of the nutrients to different compounds, within one cell but also how they are distributed between different plant organs; and iii) using this knowledge to develop tools that enable the improvement of the properties and quality of these compounds in the plant or in specific plant organs.

\section{Whole biomass use crops - systems integration}

Let's look into the plants of today: The plant uses sun energy, water and nutrients to produce all its biomass, but for most of the crops we only use efficiently a fraction of the biomass.

Take a tomato plant as an example, we only use the fruits for food and the rest of the 
biomass is a waste stream or not used efficiently. The rest of the plant has interesting components, such as proteins, lipids and carbohydrates which potentially could be used for food and non-food products. The main reason why biomass is not fully used is due to the fact that it is not economically viable to process it into products and that is because the plant has not been designed/bred to be used. For centuries we have been interested in the tomato fruits and breeding has therefore focused on the quantity and quality of the fruits.

The development of crops for whole biomass use requires a system integration approach, and this is where the research of my team will focus on. The development of such crops would have benefits at different levels and for different stakeholders: i) for the environment, as we would be more efficient in the use of resources and therefore would require less land to produce biomass for our needs; ii) for the farmers, they would get more profit as the side stream would have an economic value; iii) for the plant breeder, as they could sell their seeds for higher prices; iv) for the processor, as they would have access to biomass with good properties for a lower price.

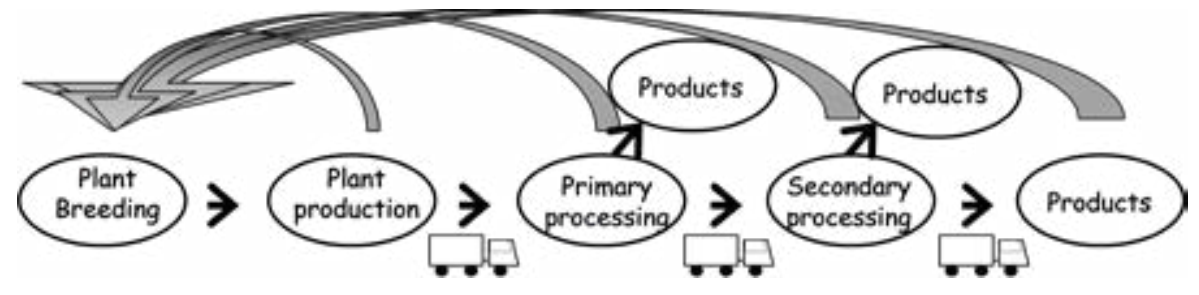

Figure 3: Breeding for new crops requires input from the different components of the production chain (Trindade et al., 2010).

To develop such crops, breeders need input from different components of the production chain (Figure 3). As breeders we need to understand from

- the farmer which type of crop they want to have? Which production system will they use to grow the crop? When and how they want to harvest the biomass?

- the processor what products they want to make from the biomass so that we can build the biomass with the right components with the required properties. On the breeding side we can improve crops that are suitable for the biorefinery, and further in this document I will explain how process biotechnologists and plant scientists can synergise to develop better crops and better processes.

- the consumer which products they want to have? Provided all safety issues have been checked, most consumers would probably be willing to eat proteins from tomato stems, but would they also be willing to use components of manure in their diet? 
The development of better Bioresources, suitable for a circular and biobased economy, requires a multidisciplinary and multi-actor approach and I believe WUR has an excellent position to address these complex questions. We have the knowledge, excellent experts in many different disciplines at the 5 Science groups and WFSR. We also have good connections with the different ministries of the Dutch government and we need to align even further our research strategy with policy makers, at national, EU, and international levels. We have an excellent engagement with industry, we are preferred partners of, for example, many breeding companies. And finally we need a better engagement of the consumers in our research, in the end they will be the one deciding what they want to consume.

\section{Development of bioresources requires an interdisciplinary and transdisciplinary approach}

The development of Bioresources for a Circular and Biobased Economy requires a system integration approach in which the knowledge and synergies between multiple disciplines and stockholders are explored. One important question that needs to be answered is: What are the crops \& plant components that can be economically and sustainably used for food, feed \& non-food products while fulfilling safety issues? The colours of the words correspond to the colours of the disciplines as represented in Figure 4.

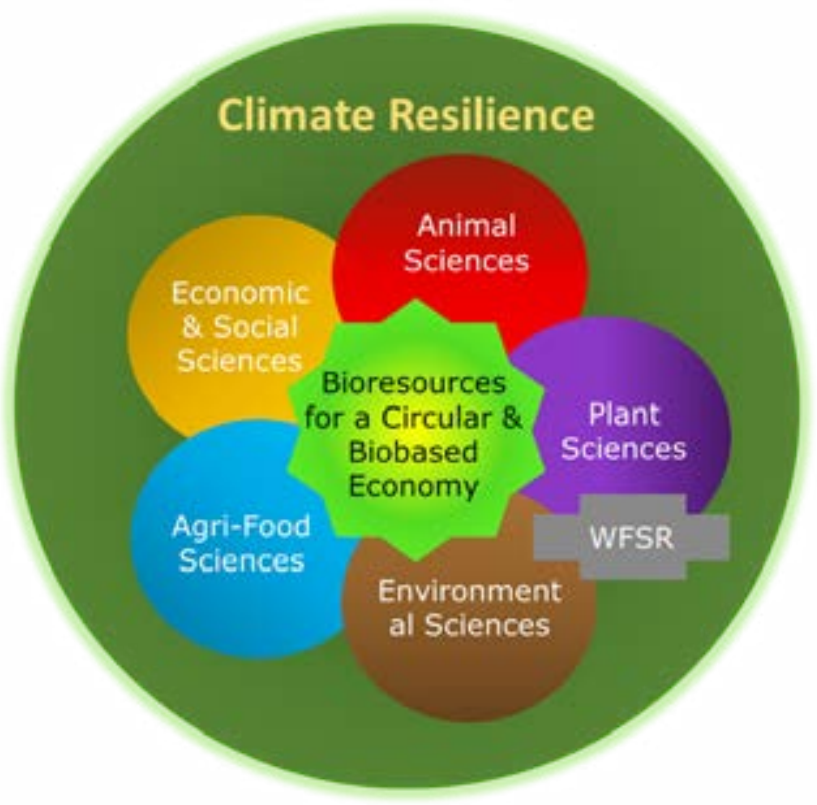

Figure 4: Development of

Bioresources requires an interdisciplinary and transdisciplinary approach 
During my lecture I will dissect this question and explain how I have and will continue developing tools to breed for bioresources by exploring synergies between different disciplines (Figure 4). I will answer the following queries:

- How can we optimize plant biomass for biorefineries?

- Which crops or parts of the crop will we use to fulfil our protein needs for food and feed?

- How can we use marginal soils to produce (which) crops for the production of (non)-food products, economically? And can we develop crops for nature inclusive agriculture?

- Which crops or parts of the crop, growing where, will be used for animal feed?

\section{How can we optimize plant biomass for biorefineries?}

Current bio-refineries have been designed to process and convert biomass, often waste streams, that require large amounts of energy and/or harsh pre-treatments. This, on the one hand, makes processing expensive and, on the other hand, it confines the environmental advantage of bioresources relatively to fossil resources. These severe pre-processing steps are also a disadvantage for the quality of the products. A few months ago, together with the group of Prof. Bitter, we have published an opinion paper on how to design the new biorefineries using a bottom-up approach. This was the result of truly sharing a postdoc researcher between the two labs, and provided both groups with a better understanding of the challenges in both disciplines. In this article we explain how we can design more effective biorefineries making use of synergies between process biotechnologist, chemists and plant breeders. The first step is to analyse genetic diversity with a multidisciplinary team of process biotechnologists, and identify molecules of interest with the right properties. This step is followed by the identification of strategies to extract these compounds using low input methods and maintaining their properties. Based on that we can develop crops that are better suited for processing, for example, where components can be efficiently extracted using milder processes or new possibilities for the separation of the different components.

An example of how we can improve extractability of cell wall components using an interdisciplinary approach is depicted in Figure 5. For most crops there is naturally a large genetic diversity in the composition and structure of the different cell wall polymers. The cell wall polymers have different properties, some strengthen the cell wall while others make the cell wall more flexible or elastic. Different combinations of these polymers result in different properties and functionalities of the cell wall. One strategy to facilitate the deconstruction of the cell wall is to include weak points 
in the cell wall matrix, so that these can be easily targeted during mild pre-processing and thus making processing steps more efficient and sustainable. This might look like a straightforward approach, but in fact it is complex as we need to ensure that the new developed plant keeps its architecture and robustness and copes well with biotic and abiotic stresses.

1

Genetic diversity

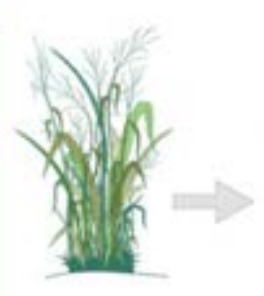

Plant Scientists \&

Chemists \& Process Biotechnologists

3

Improve crops

(build weak points in matrix)

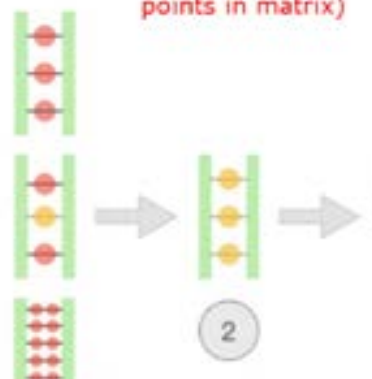

Plant Scientists
Develop and optimize processes

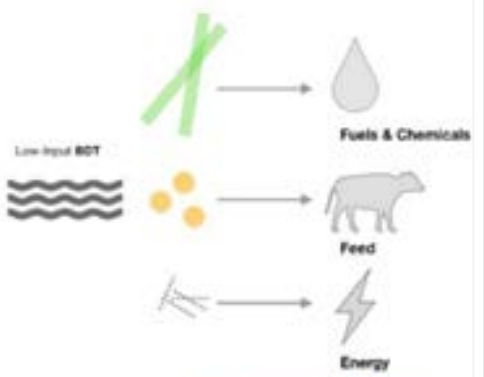

Chemists \& Process Biotechnologists

Figure 5 - Designing biorefineries bottom - up (Torres et al., 2019).

\section{Plant cell walls and biomass recalcitrance}

Cell walls are structural layers surrounding many types of cells, namely all plant cells, where they play important roles in cell morphology and consequently plant architecture. Plants, contrary to animals, cannot move and the cell wall protects the plant from biotic and biotic constrains. Cell walls have evolved into recalcitrant structures able to protect the cell, and developing crops better suited for biorefineries implies doing the opposite of what natural selection/evolution has done so far. Thus while breeding for cell walls more amenable for processing we need to make sure not to compromise the capacity of the plant to defence from biotic and abiotic stress and/ or plant architecture.

In higher plants, cell walls consists of a network of rigid cellulose microfibrils which are embedded in a dynamic matrix of non-cellulosic polysaccharides, lignin, structural proteins and other minor aromatic components. During cell division and growth, all plant cells deposit a primary cell wall which is characteristically thin and predominantly composed of complex polysaccharides, such as pectins, and highly 
glycosylated proteins. This primary cell wall compresses, shapes and imparts rigidity to the growing cell, while simultaneously allowing for the expansion of the latter. Certain cell types, which have ceased enlarging and are typically subject to mechanical stress (i.e. fiber cells in wood), will deposit an additional cell wall layer composed by polymers that provide strength to the cell. Lignin plays a major role in strengthening of the cell and is accountable for biomass recalcitrance.

Lignin occupies the spaces between the different cell wall polysaccharides and it acts like concrete in binding together different components of the cell wall. It is a complex biopolymer composed of different amounts of mostly three monolignols: p-coumaryl alcohol (H unit), coniferyl alcohol ( $\mathrm{G}$ unit), and sinapyl alcohol (S unit), represented in Figure 6 in blue, green and red, respectively. The other units, like the ones represented by $\mathrm{T}$ or I, are present only in certain plant species. These units all have different structures and they confer different properties. Also the decorations of these units are very important for the functionalities of lignin (example in Hilgers et al., 2019). In a collaboration with the groups of Dr. Kabel and Prof. Vincken (at Food Chemistry Department WU), we are working on understanding the properties of each of these units in respect to degradability of biomass and in parallel characterizing their role in plant architecture. This knowledge will enable us to better understand lignin and how to build weak points in the lignin structure that facilitates the degradation of biomass.

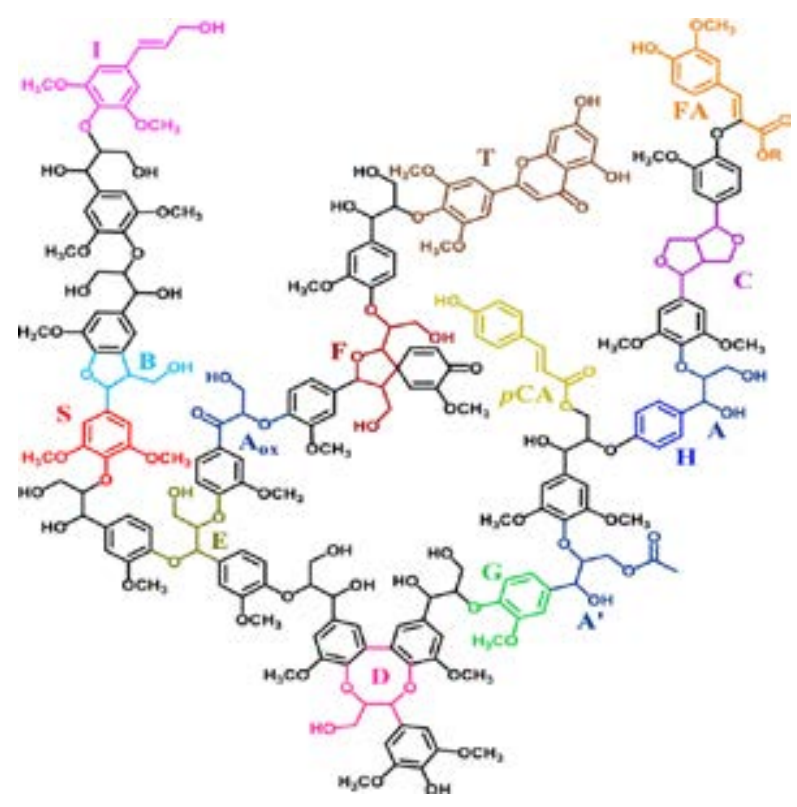

Figure 6-Model of lignin structure (Erven et al., 2018). $H$ : p-hydroxyphenyl unit; $G$ : guaiacyl unit; S: syringyl unit; $A$ : $\beta-O-4^{\prime}$ alkyl-aryl ether; $A^{\prime}: \beta-O-4^{\prime}$ alkyl-arylether $\gamma$-acylated; Aox: $\beta$-O-4'alkyl-aryl-ether C $\alpha$-oxidized; B: phenylcoumaran; $C$ : resinol; $D$ : dibenzodioxocin; $E$ : $\alpha, \beta$-diarylether; $F$ : spirodienone; I: cinnamyl alcohol (or aldehyde); $T$ : tricin; $p C A$ : $p$-coumarate; FA: ferulate $(R=H$ or arabinose $)$. 
Both p-coumarate (pCA) and ferrulate (FA, Figure 6) play important roles in linking lignin to other cell wall polysaccharides. Modulating these two molecules could provide new opportunities to change the properties of the cell wall. In our genetic studies in maize, in collaboration with Limagrain and Danisco, we have observed that these ester-linked units, in particular di-ferrulates, are more abundant in high yielding excellently digestible varieties of maize than in the highly digestible and lower yielding mutants (Torres et al., 2015, Torres et al., 2016).

\section{Breeding to facilitate extraction of novel starches}

Before starch can be used for most industrial applications it needs to be derivatized, meaning that it needs to undergo chemical or physical processing such as esterification, oxidation, phosphorylation or treatment with acid, among others. These are often expensive processes that require considerable amounts of energy and chemicals. One way to circumvent these processing steps is to modify the starch properties in planta. In the past decade we have developed different methods to create modified starches in different crops.

A big challenge for process technologists is to separate the different cell components, such as starch from other cell compounds. Using the methods we have developed at the Laboratory of Plant Breeding, namely the Starch Binding Domain (SBD, Qin et al., 2003), we propose to combine expertise of process technologists and plant breeders to develop crops where extraction and separation of the different components is facilitated. One example could be to alter the charges of starch in planta and this way facilitate the separation of starch from the other plant compounds (Torres et al., 2019).

\section{Exploring functionalities of proteins in agriculture side stream for food and feed}

It is clear that we need to be more efficient with our natural resources and in the context of protein transition it implies to develop more sustainable sources of protein for food and feed. The development of new plant-based protein products requires the development of new protein crops but also a more efficient use of parts of the crops that are currently discarded, the agricultural side streams.

To map and explore the functionalities of agriculture side streams we set up a collaborative project with the Laboratory of Food Chemistry (Dr. Wierenga) and with the Animal Science Group (Dr. Krimpen) to investigate protein functionalities relevant for food and feed applications in stems, leaves, roots and pods of different 
crops including potato, tomato, pea and lettuce. This project is currently running and is the basis for future collaborations.

I would like to mention a successful example of valorising side streams of crops. Potato has a relatively low protein concentration in the tubers, up to about $3 \%$ protein. Given the very large yield of the crop which can go up to 80 ton/ha, per ha potato produces an amount of protein that is comparable (or higher) to that of soybean, under the Dutch or European climate. Upon starch extraction there is a high volume of biomass, which includes a considerable amount of protein, left behind. AVEBE, a big producer of potato starch, has initially discarded this portion of the biomass but nowadays this fraction is well exploited by Solanic (a daughter company of AVEBE) and is an important factor for the economic value of starch potatoes. The revenue per gram of protein is higher than that of $1 \mathrm{~g}$ of starch. The breeding targets of starch potato have, therefore, focus not only on improving the content and quality of starch but also on the content and functionalities of proteins in the tuber.

\section{Optimizing the quality of protein crops}

The shift to a more plant based diet implies the development of new products that will replace animal based products. These include fresh, dried and processed plant organs, such as seeds, fruits, tubers and leaves. The conversion of agricultural products into food such as meat replacers comprise processing steps that can lead to the alteration of plant components, such as fatty acids, that generate off-flavours. Together with Wageningen Food and Biobased Research, under the coordination of Dr. Pyett, we have set up a research project to identify bottlenecks in processing of pulses into food products and resolve them with breeding (Figure 7).

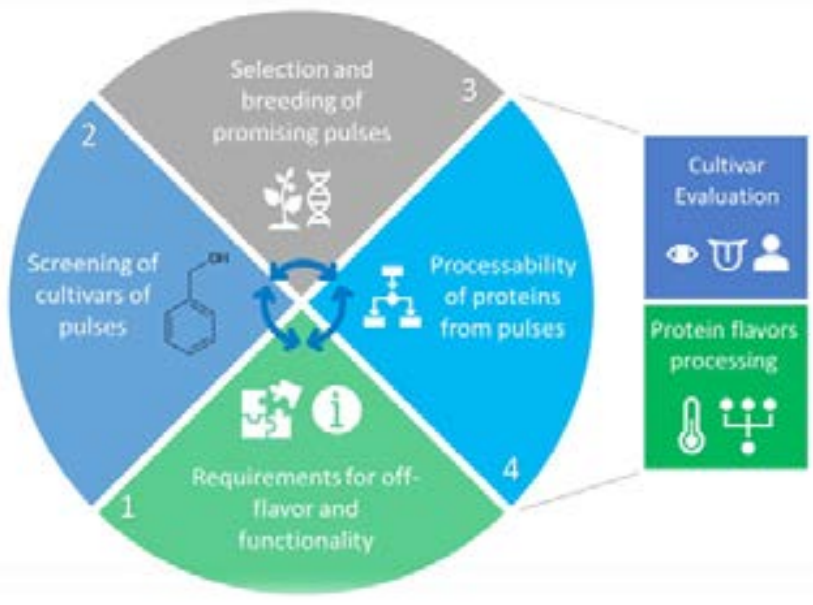

Figure 7: Systems integration to develop pulses without off-flavours and with improved functionality proteins. TKI project pulses without off flavours. 


\section{Promising protein crops for Europe}

Efforts to develop tools to breed climate-resilient crops with considerable amounts of protein (protein crops) that are well adapted to European conditions are mostly isolated and not comprehensive. This is a major bottleneck to diversifying the cultivation of protein crops in Europe and the development of better varieties is needed to ensure that cultivation of these crops is economically viable. Both from a soil quality perspective and protein content and quality point of view, legume species bare great potential, as they are able to fixate atmospheric nitrogen and thus preclude the use of $\mathrm{N}$ fertilizers. In addition, several species have high yields and the protein is often rich in some of the essential aminoacids. Examples of promising legume species include faba bean, for its high potential yield, pea, the most advanced for use in processed food from European adapted species, and lupins, for the high protein content and very low starch content.

The Andean lupin (Lupinus mutabilis), a new world lupin, could be a crop with potential for Europe on a medium term, owing to its protein content and composition and hardly any starch in the seeds. Furthermore, this crop produces the large biomass yields, in terms of leaves and stems, that are well suited for biobased applications. The development of European varieties is the focus of the European project LIBBIO, where we collaborate with Vandinter Semo who will soon release a first variety of this crop into the European market.

One other crop that is very interesting for Europe, as a source of proteins, is quinoa. Although this crop has a lower content of protein that that of legumes, about 10-15\%, it has all the necessary ingredients of a staple crop. Furthermore, it is robust crop and tolerance to very high concentrations of salt.

\section{Industrial crops for marginal lands}

MAGIC and GRACE are two EU-H2020 consortia which I am part of with focus on the development of industrial crops for marginal lands. In MAGIC we evaluate different crops, including oil-, lignocellulosic-, carbohydrate- and speciality crops (including protein crops as quinoa and lupins) on different locations with different marginal conditions (Figure 8) while in GRACE the focus is on miscanthus and hemp. Both consortia comprise academic and industrial experts at different levels of the production chain and in MAGIC WUR participate with experts of three science groups, Agri-food Sciences, Environmental Sciences and Plant Sciences.

More specifically, in these projects, we aim to identify industrial crops that tolerate specific constrains, that are efficient in the use of resources and for which cultivation 


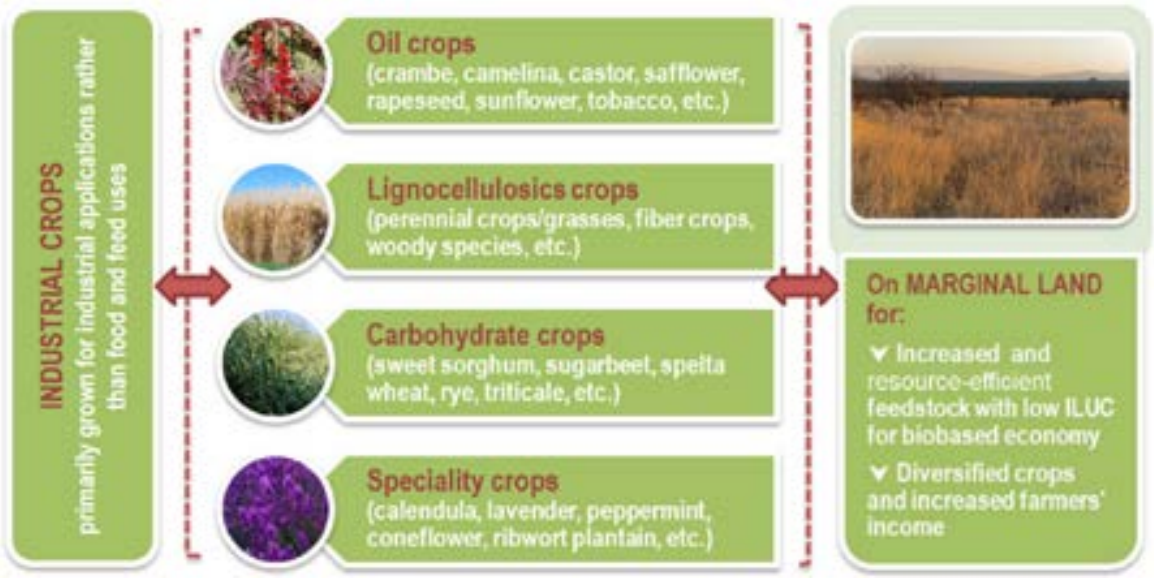

Figure 8: Flowchart of the EU-H2O2O project MAGIC (Marginal Lands for Growing Industrial Crops. Turning a Burden into an Opportunity). Further details in http://magic-h2ozo.eu/.

is economically feasible on land that is currently not used (not suitable) for agriculture, marginal land.

The reason why marginal land is not being used for agriculture is that food crops are not able to grow, or when they do the yield is drastically lower than arable soils. As a result the costs for the production of these crops are higher than the revenues and consequently not an attractive option for farmers.

Recently we have uncovered that for some industrial crops cultivation on marginal conditions can be economically viable and the constrain can even have a positive effect on biomass quality (van der Weijde et al., 2017).

\section{Miscanthus sinensis: an industrial crop with potential, also for marginal land}

Miscanthus sinensis is a beautiful grass, often found in gardens as an ornamental plant species (Figure 9). It was through the ornamental market and national gardens that this species, originary from Eastern Asia, was introduced in Europe more than one century ago.

Miscanthus is a high-yielding rhizomatous perennial grass that can grow up to 7 meters and yield up to more than 40 ton of dry matter per ha. The large biomass 
yields can be used for many different applications, including biomaterials (e.g. bioplastics, light weight concrete, isolation materials, bedding), biofuels (e.g. bioethanol and biogas) and biochemicals (e.g. bio-pesticides). Furthermore, this robust grass is tolerant to different abiotic stresses and only a few pathogens have been able to infect miscanthus but their effects on crop performance and biomass quality are limited.

The high productivity of miscanthus is related to different aspects. Firstly, miscanthus is a $\mathrm{C}_{4}$ crop, meaning that it is able to convert more efficiently solar energy and $\mathrm{CO}_{2}$ into biomass, due to their photorespiration-suppressing modifications. Secondly, unlike most $\mathrm{C}_{4}$ plants, it is cold tolerant and able to maintain photosynthetic activity at temperatures as low as $10^{\circ} \mathrm{C}$. These properties allow for early spring emergence and subsequently a comparably longer growth season than many other crops, such as maize.

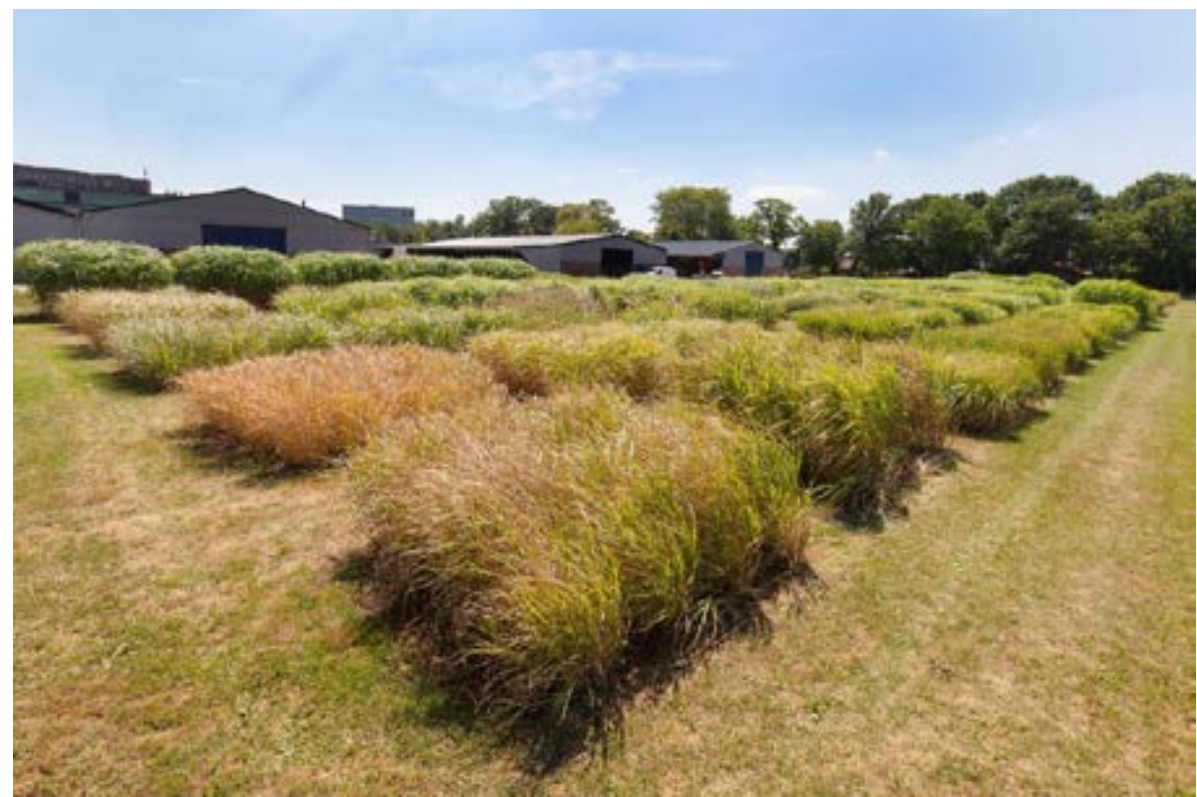

Figure 9: Miscanthus sinensis collection at Wageningen University \& Research.

Another interesting feature of miscanthus is its lower requirements in fertilizer, in particular nitrogen, owing to its ability to translocate minerals to the rhizomes at the end of the growth season. The recycling of nutrients through a rhizomatous growth habit also reduces the amount of nutrients removed from the soil by harvesting only the above-ground biomass (Lewandowski et al., 2003). 
One last feature I want to mention is the very close phylogenetic proximity between miscanthus and sugarcane. These two species are so close that crosses between them can be made, and that results in interspecific hybrids. Ideally we would like to combine the cold tolerance of miscanthus with the production of sugar in sugarcane. Currently I am collaborating with colleagues in Brazil, Argentina and South Africa to develop such hybrids.

Regarding the suitability of miscanthus for marginal lands, we have tested the effects of drought on 50 genotypes of Miscanthus sinensis and observed overall a decrease in yield, some genotypes more severely than others and on average a $40-45 \%$ total biomass reduction (blue line in Figure 10). In this same experiment we have observed that the saccharification efficiency (here expressed as cellulose conversion, green and pink bars), a measure of efficiency to convert biomass into bioethanol, was much higher for all genotypes grown under stress conditions. Corresponding to quality improvement in the order of $35-40 \%$ for most of the lines (Figure 10).

This means that if we would use the biomass of miscanthus for producing bioethanol, for several genotypes we would have comparable amounts of bioethanol produced from the plants that have been grown under drought as the ones that were irrigated. This opens new opportunities for growing miscanthus on marginal land where water availability is a limiting factor.

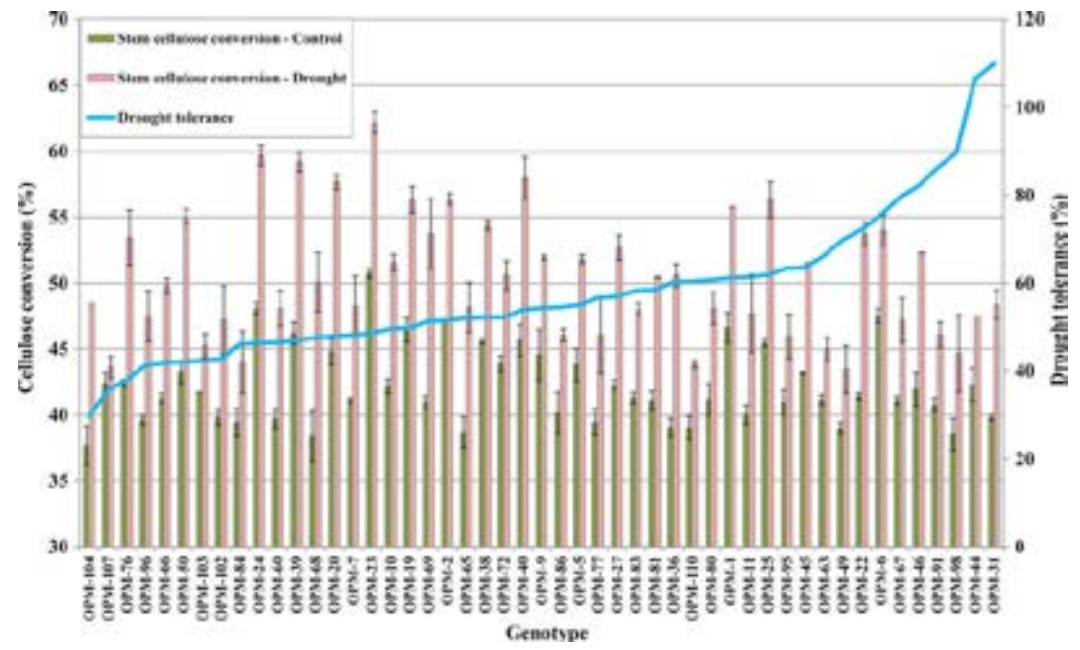

Figure 10: Drought tolerance and cellulose conversion of 50 accessions of Miscanthus sinensis. Adapted from van der Weijde et al. (2017) 


\section{Intercropping for feed}

I would like to go now into my last research question on which crops or parts of the crop, growing where, will be used for animal feed?

Intercropping of maize and legumes, such as different types of beans, has been widely used for many years as a way to increase crop production and resource efficiency in areas of intensive agriculture. In intercropping systems at least two crops are grown in the same land for a certain period of time. Other benefits of this cropping system include the lower incidence of diseases, pests and weed damage relatively to the cultivation of only one crop. In addition, specifically for maize and legumes, the legume will provide additional nitrogen for the maize, circumventing extra fertilization, and the maize will in turn provide the support for the beans to climb up.

This system has mainly been used for food purposes and that means that the edible parts of the different crops would have to be harvested independently. In most cases this implied that harvest could not be mechanical but would have to be done manually. This is in fact one major bottleneck that prevented a further widespread of this system in agricultural regions that are (highly) mechanized and with high labour prices.

One other system I could think of is using these crops for feed in a mix, a silage like mix, with the right equilibrium in fibre and protein. In this case harvest can be done mechanically and the benefits of intercropping can be explored. This new system will require new varieties, both of maize and legumes, that are optimized for intercropping, as well as new cropping systems that allow the right mix of the two crops for silage. We are working with breeding companies to give body to this concept.

For the development of such production system we will need new breeding tools including new breeding methods, in particular for legumes where less breeding tools are available. And we will also need tools for high-throughput phenotyping to evaluate the large number of lines that are required in the breeding programme.

\section{Conclusions}

Throughout my lecture I presented my vision on how to develop Bioresources for a Circular and Biobased Economy. I showed that crops need to be re-designed to be more efficient in the use of resources; they need to be more resilient and robust and be able to grow economically on agricultural soils but also on marginal soils. We also have to accommodate nature and biodiversity and a new target would be breeding towards nature inclusive agriculture. 
I also showed that we need to be more efficient in the use of the plant biomass we produce and that requires developing crops for whole crop use.

To reach this objective we need a multidisciplinary and a multi-actor approach and this is at the core of WUR strategy.

\section{My vision on Education at Wageningen University \& Research}

Multidisciplinary/interdisciplinary and international Alliances are two major aspects that form the basis of my vision on education at different levels, BSc, MSc and PhD. They provide excellent skills and help developing competences that will help the students to have a broader view of complex issues. For the students it is very enriching to understand the views of experts in different disciplines around a theme of their interest. One good example is the MSc Biobased Sciences where all science groups of WUR are involved. In this MSc there is room for the students to get in depth knowledge of the discipline of their interest: primary production, Biorefinery \& Conversion or Social and Economic studies, but they also follow courses that integrate knowledge of the different areas. I also like the self-reflection assignment where the students reflect on this multidisciplinarity.

Alliances with other universities create excellent opportunities for teachers to improve even further the quality of our education. Each university has experts in specific areas and together we can cover better interdisciplinary education, while ensuring education by the best experts. Very importantly, university alliances provide very enriching opportunities for our students to experience other education and cultural environments. Two very interesting examples of university alliances are the $\mathrm{A}_{5}$ and the European Bioeconomy University (EBU). The $\mathrm{A}_{5}$ is an alliance of the top 5 Agri-food Universities (WUR, Cornell, UC-Davis, University of Sao Paulo and Agriculture University of China) which are committed to join forces to combat hunger. EBU is an alliance of 6 European universities (WUR, BOKU, University of Eastern Finland, UniBo, HOHU and AgriParisTech) that play an important role in Education and Research in Bioeconomy.

Specifically in the area of Plant Breeding, what I observe is that animal breeders and plant breeders use different breeding strategies and tools. While animal breeding aims to breed for millions of genetically diverse organisms, plant breeders aim to homogenize and target to genetically similar organisms (Figure 11). These two very different strategies are both successful and I believe that our breeders would greatly profit from learning about both animal and plant breeding. The collaboration between plant breeding and animal breeding experts would also greatly contribute to 
the development of new breeding methods and tools. For example plant breeders could learn from the success of breeding animals that are fully and efficiently used, to develop crops for whole biomass use.

Animal breeding

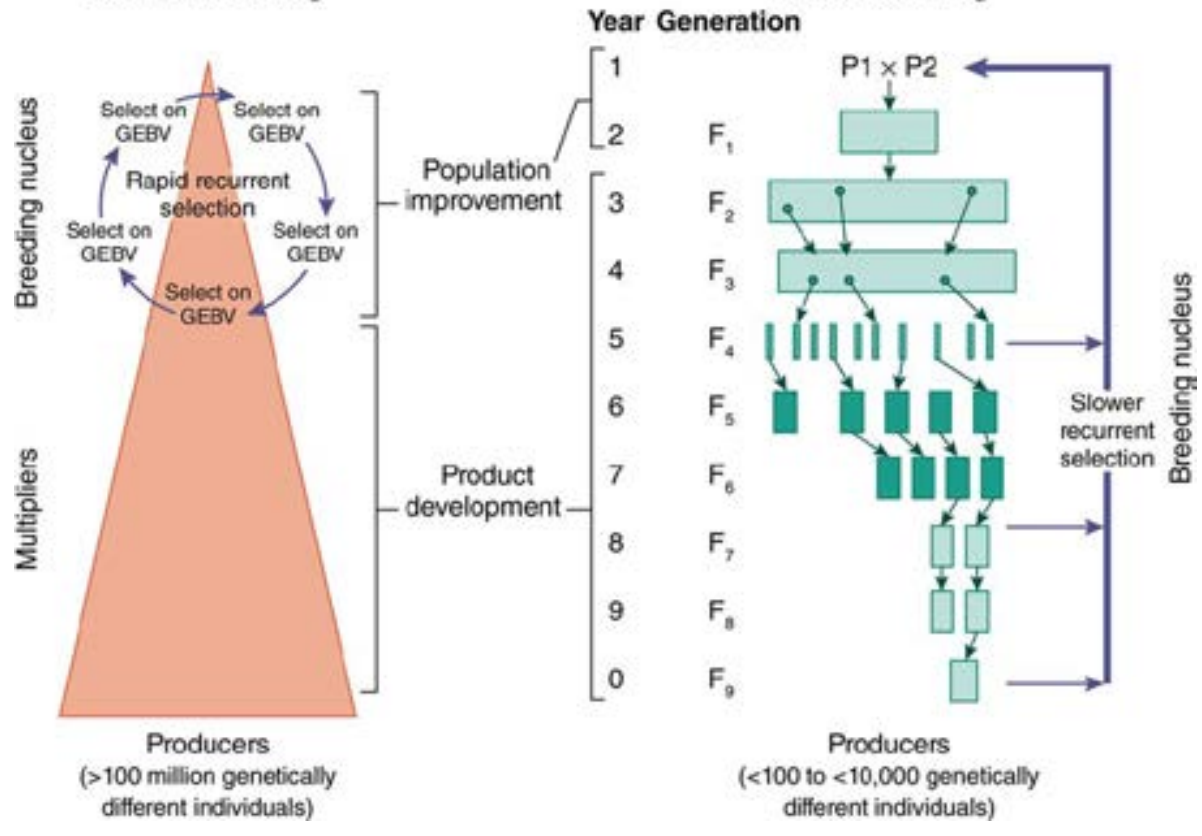

Figure 11: Comparison of animal and plant breeding approaches (Hickey et al., 2017)

\section{Acknowledgements}

This brings me to the end of my inaugural address. I thank the board of Wageningen University, Arthur Mol, Rector Magnificus and Louise Fresco, President of Wageningen University \& Research, for granting me the honour to serve as Professor at Wageningen University.

All the research I have presented would not have been possible without the excellent researchers of the Biobased Economy team, the present and the past members. I am deeply grateful for the excellent work delivered by each and every one of you. I am very proud of what we achieved in the past 12 years at the scientific level. I am also 
very proud of the excellent atmosphere in the team! To all of you a big big Thank you!

I would also like to thank my mentors. I would like express my gratitude to my $\mathrm{PhD}$ supervisors Richard Visser and Evert Jacobsen. Richard thank you for your help and supervision, in particular at the early stages of my career. Evert, thank you for being a great discussion partner, both for scientific and less scientific issues. Although retired you always made time for me. To Ernst van den Ende I am very grateful for your guidance and coaching, in spite of your very busy diary you always found time to meet me.

I reserve the last acknowledgements for my family, and excuse me for swapping between Portuguese, Dutch, and English.

Pai e mae, muito obrigada pela infancia despreocupara que me proporcionaram. Estou muito grata por todo o apoio e interesse durante toda a minha vida e carreira. Um muito obrigado tambem para os meus irmaos e cunhado. Monica, Nuno e Ze obrigado pelos excelentes momentos que passamos juntos; e naturalmente as minhas sobrinhas: Leonor, Madalena, Francisca e Catarina. Obrigado a todos por estarem aqui neste momento tao importante para mim!

Mijn Nederlands familie, Marianne, Peter en Paul. Dank jullie wel voor de steun dat jullie al deze jaren aan mij hebben gegeven en voor jullie geduld. Ik ben niet de makkelijkste, speciaal tijdens mijn meest stressvolle momenten. Ik wil ook de hele familie van Gerven en Traa bedanken voor jullie steun en voor jullie aanwezigheid, en speciale dank aan mijn neven Bas en Mark vandaag hier op het podium.

And my final words go to the ones that deserve the first place: my two stars Rob and Lieke. There are no words to express my gratitude for your continuous and unconditional support, thank for your endless patience and above all, for your love!

Ik heb gezegd 
Hickey J.M., Chiurugwi T., Mackay I., Powell W. 2017. Genomic prediction unifies animal and plant breeding programs to form platforms for biological discovery. Nature Genetics. 49(9):1297-1303.

Hilgers R., Tweentyman-Jones M., van Dam A., Gruppen H., Zuilhof H., Kabel M.A., Vincken J-P. 2019. The impact of lignin sulfonation on its reactivity with laccase and laccase/HBT. Catalysis Science \& Technology. 9: 1535-1542

Lewandowski I., Scurlock J.M.O., Lindvall E., Christou M. 2003. The development and current status of perennial rhizomatous grasses as energy crops in the US and Europe. Biomass and Bioenergy. 25: 335-361.

Torres A.F., Noordam-Boot C.M.M., Dolstra O., van der Weijde T., Combes E., Dufour P., Vlaswinkel L., Visser R.G.F. and Trindade L.M. 2015. Cell wall diversity in forage maize: genetic complexity and bioenergy potential. Bioenergy Research. 8(1): 187-202

Torres A.F., Slegers P.M., Noordam-Boot C.M.M., Dolstra O., Vlaswinkel L., van Boxtel A.J.B., Visser R.G.F., Trindade L.M. 2016. Bioenergy feedstocks with improved digestibility upgrade the commercial and environmental performance of cellulosic fuels. Biotechnology for Biofuels. 9:63. DOI: 10.1186/s13068-016-0479-0

Torres A.F., Xu X., Nikiforidis C.V., Bitter J.H., Trindade L.M. 2019. Exploring the Treasure of Plant Molecules With Integrated Biorefineries. Frontiers in Plant Sciences. doi.org/10.3389/fpls.2019.00478

Trindade L., Dolstra O., van Loo. E.N., Visser R.G.F. 2010. Plant Breeding and its role in a Biobased Economy. In: The Biobased Economy: Biofuels, Materials and Chemicals in the Post-oil Era. Ed. Langeveld, Meeusen and Sanders. Earthscan Publications. Pag. 67-82. ISBN 9781844077700

van der Weijde T., Huxley L.M., Hawkins S., Sembiring E.H., Farrar K., Dolstra O., Visser R.G.F., Lewandowski I., Trindade L.M. 2017. Impact of drought stress on growth and quality of miscanthus for biofuel production. GCB Bioenergy. 9(4): 770-782. 



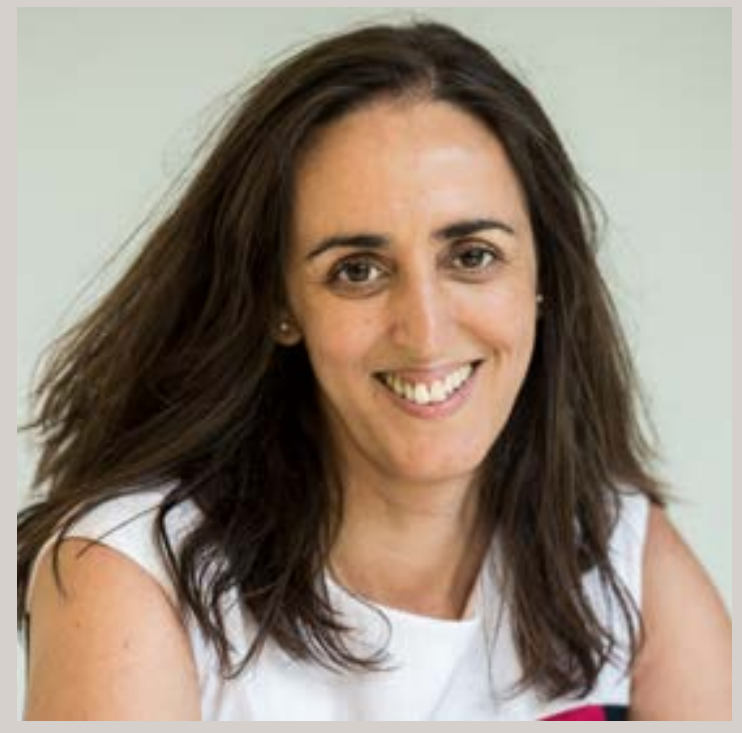

Prof.dr. Luisa M. Trindade

'We are facing major global challenges, a rapidly increasing population, climate change, decline in biodiversity. To feed healthily, equitably and sustainably the growing population, while preserving the ecosystem we need to be efficient in the use of our natural resources. The Personal Chair of "Bioresources Breeding and Genetics" aim to create tools to redesign our crops, to develop whole-biomass-use crops that are efficient in the use of natural resources. An interdisciplinary integrative approach is required to address this complex question.' 